\title{
Treatment of posthemorrhagic ventricular dilation in preterm infants: a systematic review and meta-analysis of outcomes and complications
}

\author{
Jetan H. Badhiwala, MD, ${ }^{1}$ Chris J. Hong, BHSc, ${ }^{2}$ Farshad Nassiri, MD, ${ }^{1}$ Brian Y. Hong, BHSc, ${ }^{2}$ \\ Jay Riva-Cambrin, MD, MSc, ${ }^{3}$ and Abhaya V. Kulkarni, MD, PhD ${ }^{1}$ \\ 'Division of Neurosurgery, The Hospital for Sick Children, University of Toronto; 'Faculty of Medicine, University of Ottawa, \\ Ontario, Canada; and 'Division of Pediatric Neurosurgery, Primary Children's Hospital, Department of Neurosurgery, University \\ of Utah, Salt Lake City, Utah
}

\begin{abstract}
OBJECT The optimal clinical management of intraventricular hemorrhage (IVH) and posthemorrhagic ventricular dilation (PHVD)/posthemorrhagic hydrocephalus $(\mathrm{PHH})$ in premature infants remains unclear. A common approach involves temporary treatment of hydrocephalus in these patients with a ventriculosubgaleal shunt (VSGS), ventricular access device (VAD), or external ventricular drain (EVD) until it becomes evident that the patient needs and can tolerate permanent CSF diversion (i.e., ventriculoperitoneal shunt). The present systematic review and meta-analysis aimed to provide a robust and comprehensive summary of the published literature regarding the clinical outcomes and complications of these 3 techniques as temporizing measures in the management of prematurity-related PHVD/PHH.

METHODS The authors searched MEDLINE, EMBASE, CINAHL, Google Scholar, and the Cochrane Library for studies published through December 2013 on the use of VSGSs, VADs, and/or EVDs as temporizing devices for the treatment of hydrocephalus following IVH in the premature neonate. Data pertaining to patient demographic data, study methods, interventions, and outcomes were extracted from eligible articles. For each of the 3 types of temporizing device, the authors performed meta-analyses examining 6 outcomes of interest, which were rates of 1) obstruction; 2) infection; 3 ) arrest of hydrocephalus (i.e., permanent shunt independence); 4) mortality; 5) good neurodevelopmental outcome; and 6) revision.
\end{abstract}

RESULTS Thirty-nine studies, representing 1502 patients, met eligibility criteria. All of the included articles were observational studies; 36 were retrospective and 3 were prospective designs. Nine studies $(n=295)$ examined VSGSs, $24(n$ $=962)$ VADs, and 9 ( $n=245)$ EVDs. Pooled rates of outcome for VSGS, VAD, and EVD, respectively, were $9.6 \%, 7.3 \%$, and $6.8 \%$ for obstruction; $9.2 \%, 9.5 \%$, and $6.7 \%$ for infection; $12.2 \%, 10.8 \%$, and $47.3 \%$ for revision; $13.9 \%, 17.5 \%$, and $31.8 \%$ for arrest of hydrocephalus; $12.1 \%, 15.3 \%$, and $19.1 \%$ for death; and $58.7 \%, 50.1 \%$, and $56.1 \%$ for good neurodevelopmental outcome.

CONCLUSIONS This study provides robust estimates of outcomes for the most common temporizing treatments for IVH in premature infants. With few exceptions, the range of outcomes was similar for VSGS, VAD, and EVD.

http://thejns.org/doi/abs/10.3171/2015.3.PEDS14630

KEY WORDS cerebrospinal fluid shunts; hydrocephalus; intraventricular hemorrhage; premature birth; vascular disorders

$\mathrm{T}$ HE average incidence of preterm birth in 2010 was $11.1 \%$ globally and $12.0 \%$ in the US. ${ }^{9}$ Advances in fetal medicine and obstetric and neonatal intensive care over recent decades have improved the survival of premature infants born at ever-earlier gestational ages.,462 This is perhaps one of the greatest successes of modern medicine, but one that has brought its fair share of chal- lenges. Preterm infants are at risk for multiple comorbidities, including bronchopulmonary dysplasia, necrotizing enterocolitis, retinopathy of prematurity, among others. ${ }^{17}$ Greater survival among these patients has hence translated into increased burden of morbidity. ${ }^{62}$ Intraventricular hemorrhage (IVH) and posthemorrhagic ventricular dilation (PHVD) are complications of prematurity that portend

ABBREVIATIONS EVD = external ventricular drain; IVH = intraventricular hemorrhage; $\mathrm{PHH}=$ posthemorrhagic hydrocephalus; $\mathrm{PHVD}=$ posthemorrhagic ventricular dilation; VAD = ventricular access device; VSGS = ventriculosubgaleal shunt.

SUBMITTED November 8, 2014. ACCEPTED March 26, 2015.

INCLUDE WHEN CITING Published online August 28, 2015; DOI: 10.3171/2015.3.PEDS14630. 
considerable neurodevelopmental sequelae, including cognitive delay, visual impairment, behavioral abnormalities, epilepsy, cerebral palsy, and symptomatic hydrocephalus. ${ }^{1,27,57}$ It is estimated that $25 \%-30 \%$ of premature/lowbirth-weight infants suffer from IVH. ${ }^{23,33}$ PHVD develops in $25 \%-50 \%$ of these neonates, and roughly $40 \%$ require some treatment for hydrocephalus. ${ }^{11,45,66}$

Treatment paradigms for $\mathrm{PHVD} /$ posthemorrhagic hydrocephalus $(\mathrm{PHH})$ in premature infants have shifted time and time again, and have included diuretics, serial lumbar puncture, intraventricular fibrinolytics, ventricular access device (VAD), external ventricular drain (EVD), and ventriculosubgaleal shunt (VSGS) ${ }^{59}$ To date, there remains little in the way of evidence to guide the pediatric neurosurgeon. A common approach used today is to treat PHVD/PHH with a temporizing device-most commonly, either a VAD or VSGS, and less frequently, an EVDuntil placement of a permanent ventriculoperitoneal shunt becomes a necessary and safe undertaking. The choice of temporizing measure remains a topic of heavy debate, and there have been few direct comparisons between the aforementioned methods. To that end, we undertook a systematic review and meta-analysis to provide the best estimates of various relevant outcomes of VSGS, VAD, and EVD in the management of prematurity-related PHVD/ PHH.

\section{Methods}

This systematic review and meta-analysis was conducted in accordance with the Meta-analysis Of Observational Studies in Epidemiology (MOOSE) guidelines ${ }^{63}$ and the Preferred Reporting Items for Systematic reviews and Meta-Analyses (PRISMA) statement. ${ }^{44}$

\section{Search Strategy}

We searched, without language restrictions, MEDLINE, EMBASE, CINAHL, Google Scholar, and the Cochrane Library from the start date of each source through December 2013. We looked for studies reporting clinical outcomes of the use of VSGS, VAD, and/or EVD as temporizing measures for the treatment of hydrocephalus following IVH in preterm infants. We used, in various combinations, keywords/MeSH terms related to prematurity (e.g., neonate, premature infant, prematurity, preterm infant); posthemorrhagic hydrocephalus (e.g., hydrocephalus, intracranial hemorrhage, intraventricular hemorrhage, ventricular dilation, ventriculomegaly); and pertinent methods of CSF diversion (e.g., cerebrospinal fluid shunt, McComb reservoir, Ommaya reservoir, Rickham reservoir, subgaleal shunt, ventricular access device, ventricular catheter, ventricular reservoir, ventriculostomy, ventriculosubgaleal shunt). We also manually searched the references of relevant articles to identify additional studies for consideration.

\section{Selection Criteria}

Two authors (J.H.B. and C.J.H.) independently evaluated the studies for eligibility. The inclusion criteria were: 1) population, defined as premature infants with $\mathrm{PHVD} /$ $\mathrm{PHH}$; 2) intervention, defined as VSGS, VAD, and/or EVD; and 3) outcome, defined as at least 1 of the follow- ing: obstruction, infection, arrest of hydrocephalus, mortality, neurodevelopmental outcome, or revision. Cohorts with a sample size $<10$ were excluded. For studies reporting data on overlapping cohorts from the same institution, we included only the study with the most inclusive cohort to prevent duplications. Abstracts from meeting proceedings were excluded if the data were not published as full-text articles in a peer-reviewed journal. Disagreements between the 2 reviewers concerning the decision to include or exclude a study were resolved by consensus and, if necessary, consultation with a third reviewer (A.V.K. or J.R.C.).

\section{Data Extraction}

From eligible reports, we abstracted data relating to patient characteristics, study methods, interventions, and outcomes. All data were independently extracted by the 2 primary reviewers, and verified for accuracy by the third reviewer. Discrepancies were resolved by discussion and consensus.

We abstracted the total number of events for 6 outcomes of interest: obstruction, infection, arrest of hydrocephalus, mortality, good neurodevelopmental outcome, and revision. Arrest of hydrocephalus was defined as children known, unequivocally, to be alive without having undergone permanent CSF diversion (i.e., shunt or endoscopic third ventriculostomy). Mortality included all deaths in patients who received a temporizing device (i.e., VSGS, VAD, or EVD), regardless of cause and need for permanent CSF diversion. Children with normal cognitive, language, social, and motor function, or only mild deficits in these functions, were considered to have a good developmental outcome. A revision was any operation for replacement, revision, or infection of a temporizing device.

\section{Quality Assessment}

Two reviewers performed quality assessment. We used the Newcastle-Ottawa Scale ${ }^{67}$ to evaluate comparability, selection of cohort, and assessment of outcome among eligible studies.

\section{Statistical Analyses}

Cohorts were grouped based on treatment modality: VSGS, VAD, or EVD. Because there were too few studies that provided a direct comparison of outcomes between 2 or more of these interventions, we instead performed meta-analyses for each of the 6 outcomes of interest for each intervention separately. Obstruction, infection, arrest of hydrocephalus, mortality, and good neurodevelopmental outcome were expressed as proportions based on number of patients, whereas revision rates were calculated based on number of devices.

Between-study heterogeneity was evaluated by Cochran's $Q$ test and measured by the $I^{2}$ statistic, with $I^{2}$ values exceeding $25 \%, 50 \%$, and $75 \%$ representing low, moderate, and high heterogeneity, respectively. ${ }^{24}$ The DerSimonianLaird random effects model was used to calculate pooled proportions with $95 \%$ CIs. Weights were calculated by the inverse variance method. Publication bias was evaluated visually by funnel plot analysis and quantified by Begg and Mazumdar's ${ }^{8}$ and Egger's tests. ${ }^{16}$ The threshold Type 
I error rate for statistical significance was set a priori at $\alpha$ $=0.05$ (2-tailed). We used Comprehensive Meta-Analysis version 2.2 (Biostat, Inc.) to conduct all statistical analyses.

\section{Results}

Our search yielded 1748 studies, of which 1591 were excluded after title and abstract screening (Fig. 1). An additional 118 resources were excluded following full-text review. The remaining 39 studies reporting on 1502 patients of interest were included in our systematic review and meta-analysis. There were 3 prospective observational studies; the remaining 36 studies were retrospective designs.

\section{Ventriculosubgaleal Shunt}

Nine studies $(\mathrm{n}=295)$ examined VSGSs (Table 1$).$ Pooled rates of outcome were 9.6\% (95\% CI 5.6-16.0) for obstruction, 9.2\% (95\% CI 6.3-13.3) for infection, 13.9\% (95\% CI 9.6-19.8) for arrest of hydrocephalus, $12.1 \%$ (95\% CI 5.3-25.3) for mortality, 58.7\% (95\% CI 26.8-84.6) for good neurodevelopmental outcome, and $12.2 \%$ (95\% CI 8.8-16.5) for revision (Fig. 2).

\section{Ventricular Access Device}

Twenty-four studies $(n=962)$ reported on the use of VADs (Table 2). Summary estimates were $7.3 \%$ (95\% CI 5.0-10.4) for obstruction, 9.5\% (95\% CI 7.0-12.8) for infection, $17.5 \%$ (95\% CI 13.0-23.2) for arrest of hydrocephalus, $15.3 \%$ (95\% CI 10.4-22.0) for mortality, 50.1\% (95\% CI 34.3-65.8) for good neurodevelopmental outcome, and $10.8 \%$ (95\% CI 7.4-15.5) for operative revision (Fig. 3).

\section{External Ventricular Drain}

Nine reports $(n=245)$ used EVDs to temporize PHVD in premature neonates (Table 3). Pooled event rates were $6.8 \%(95 \%$ CI 3.3-13.5) for obstruction, $6.7 \%$ (95\% CI 3.9-11.1) for infection, 31.8\% (95\% CI 21.7-43.9) for arrest of hydrocephalus, $19.1 \%$ (95\% CI 14.2-25.3) for mortality, $56.1 \%$ (95\% CI 34.8-75.4) for good neurodevelopmental

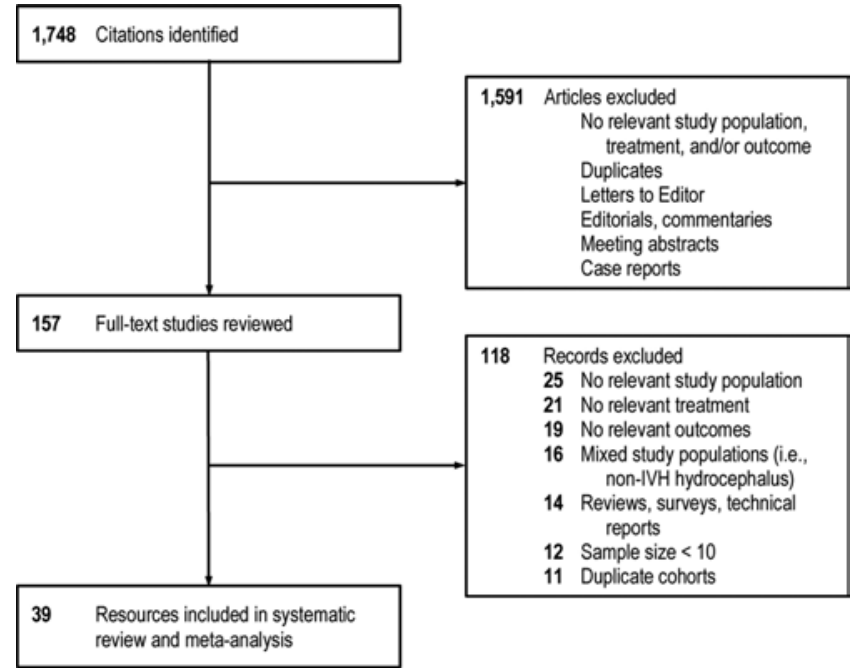

FIG. 1. A flowchart summarizing the literature search and study selection process.

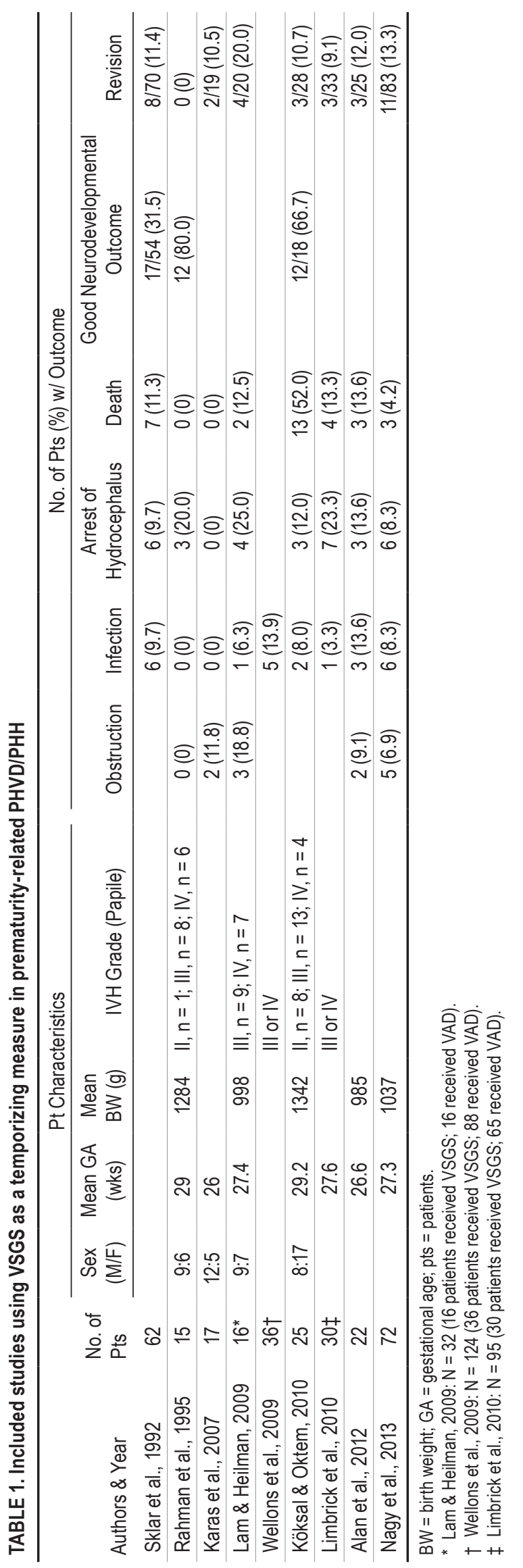


A

Study name
Rahman et al. (1995)
Karas et al. (2007)
Lam et al. (2009)
Alan et al. (2012)
Nagy et al. (2013)
Pooled estimate

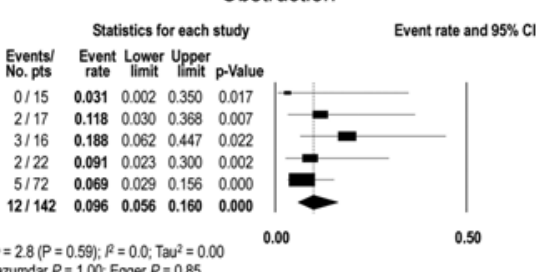

Heterogeneity: Cochran $Q=28(P=0.59) ; R=0.0 ; T^{2}=0.00$
Publication bias: Begg-Mazumdar $P=1.00 ; E$ goger $P=0.85$

B

Study name

Sklar et al. (1992)
Rahman et al. (1995)
Karas et al. (2007)
Lam et al. (2009)
Wellons et al. (2009)
Köksal et al. (2010)
Limbrick et al. (2010)
Alan et al. (2012)
Nagy et al. (2013)
Pooled estimate

Nagy et al. (2013)

Heterogeneity: Cochran $Q=4.3(P=0.83) ; R=0.0 ;$ Tau $^{2}=0.00$

Infection

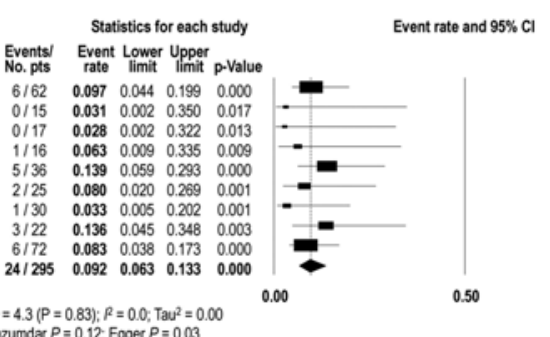

Arrest of hydrocephalus

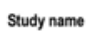

for each study

Event rate and $95 \% \mathrm{Cl}$

Sklar et al. (1992)

Rahman et al. (1995)

Karas et al. (2007)

Lam et al. (2009)

Köksal et al. (2010)
Limbrick et al. (2010)

Alan et al. (2012)

Nagy et al. (2013)

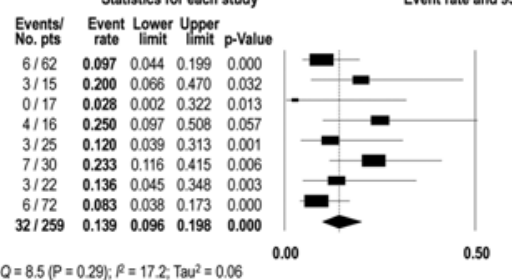

Heterogeneily. Cochran $Q=8.5(P=0.29) ; R=17.2 ; \operatorname{Tau}^{2}=0.06$
Publication bias: Begg-Mazumdar $P=0.90 ;$ Egger $P=0.71$

D

Study name

Sklar et al. (1992)

Rahman et al. (1995)

Karas et al. (2007)

Lam et al. (2009)

Köksal et al. (2010)

Limbrick et al. (2010)

Alan et al. (2012)

Nagy et al. (2013)
Pooled estimate

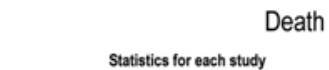

Death

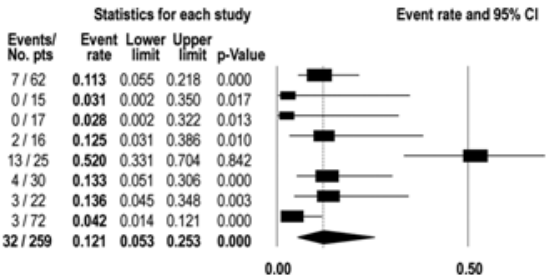

Heterogeneity: Cochran $Q=29.8(P<0.01) ; \beta=76.5 ; \operatorname{Tau}^{2}=1.16$

Publication bias: Begg-Mazumdar $P=0.39$; Egger $P=0.17$

E

Good developmental outcome

Study name

Sklar et al. (1992)

Rahman et al. (1995)

Köksal et al. (2010)

Pooled estimate

Heterogeneity Cochr Publi

F

Study name

Sklar et al. (1992) Rahman et al. (1995) Karas et al. (2007) Lam et al. (2009) Köksal et al. (2010) Limbrick et al. (2010) Alan et al. (2012) Nagy et al. (2013) Pooled estimate

Heterogeneity: Cochran $Q=27(P=0.91) ; R=0.0 ; \operatorname{Tau}^{2}=0.00$ Statistics for each study Events/ Event Lower Upper $p$ rate limit limit $p$-Value $\begin{array}{lllll}17 / 54 & 0.315 & 0.206 & 0.449 & 0.008\end{array}$ $\begin{array}{lllll}12 / 15 & 0.800 & 0.530 & 0.934 & 0.032\end{array}$ $\begin{array}{llllll}12 / 18 & 0.667 & 0.429 & 0.842 & 0.166\end{array}$ $\begin{array}{lllll}41 / 87 & 0.587 & 0.268 & 0.846 & 0.612\end{array}$

0.00

Revision

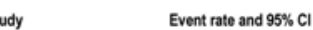
Events/ Event Lower Upper
No. devices rate limit limit p-Value
rate $\begin{array}{llllll}8 / 70 & 0.114 & 0.058 & 0.212 & 0.000\end{array}$ $\begin{array}{llllll}8 / 15 & 0.031 & 0.002 & 0.350 & 0.011\end{array}$ $\begin{array}{lllll}2 / 19 & 0.105 & 0.026 & 0.337 & 0.004\end{array}$ $\begin{array}{lllll}4 / 20 & 0.200 & 0.077 & 0.428 & 0.013\end{array}$ $\begin{array}{lllll}3 / 28 & 0.107 & 0.035 & 0.284 & 0.001\end{array}$ $\begin{array}{lllll}3 / 33 & 0.091 & 0.030 & 0.247 & 0.000\end{array}$ $\begin{array}{llllll}3 / 25 & 0.120 & 0.039 & 0.313 & 0.001\end{array}$ $\begin{array}{llllll}11 / 83 & 0.133 & 0.075 & 0.224 & 0.000\end{array}$ $\begin{array}{lllll}34 / 293 & 0.122 & 0.088 & 0.165 & 0.000\end{array}$

0.00

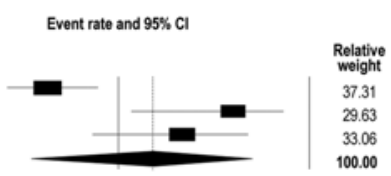

0.50

1.00

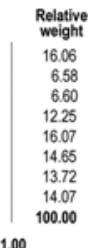

1.00

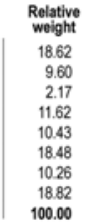

1.00

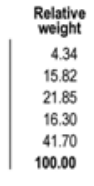

1.00

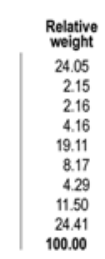

1.00 


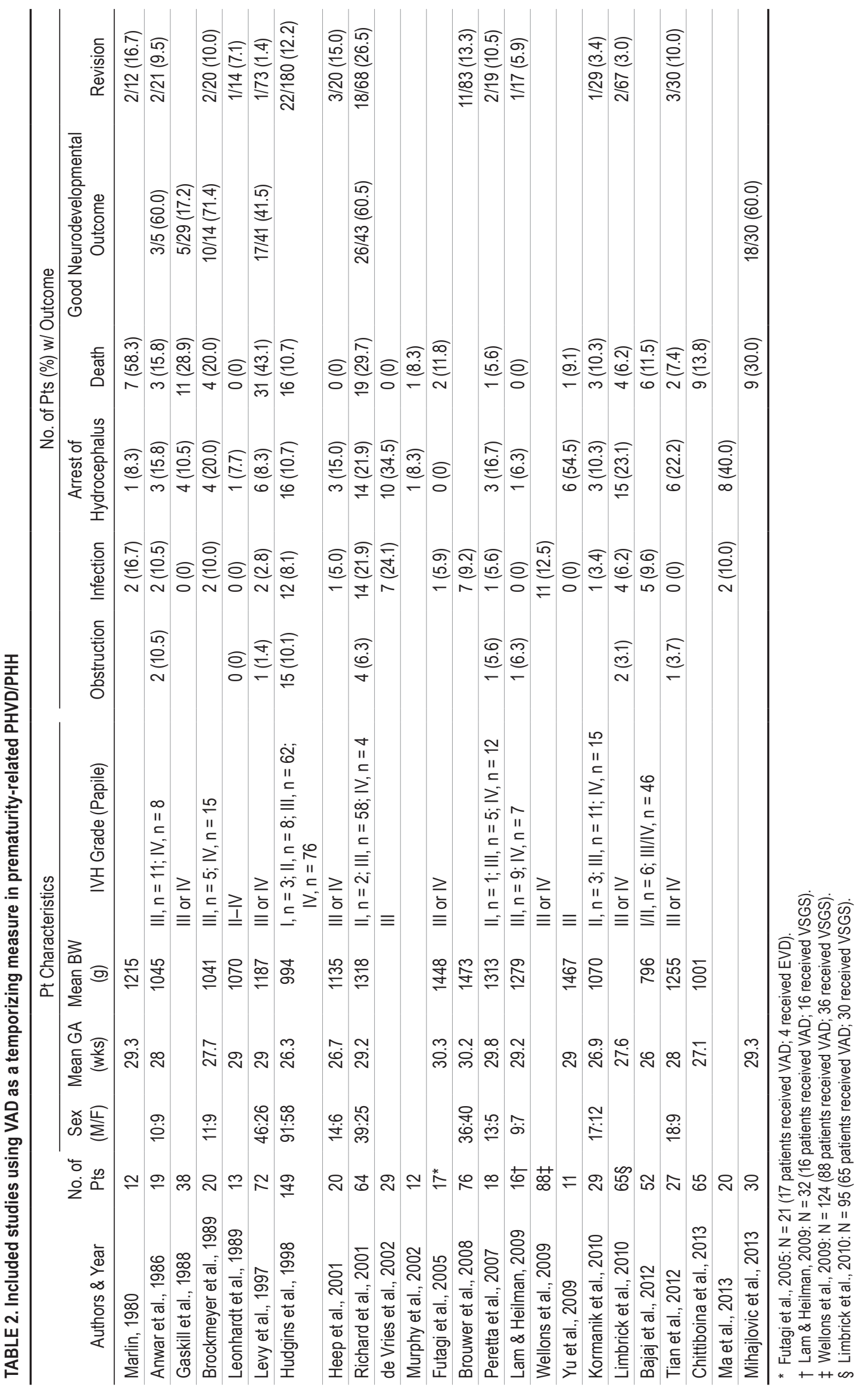


A

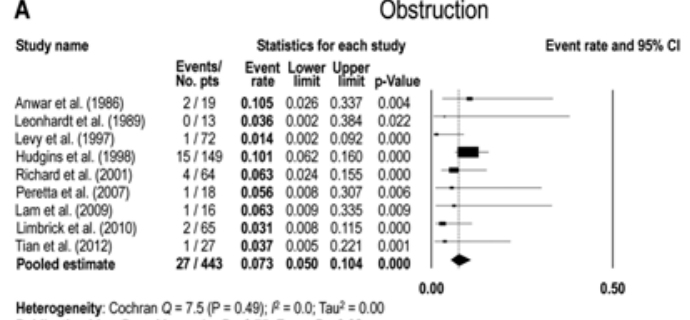

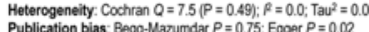

B

Study name

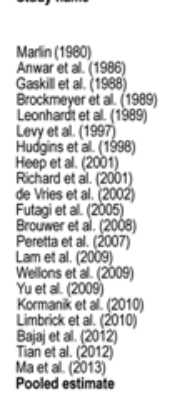

Infection

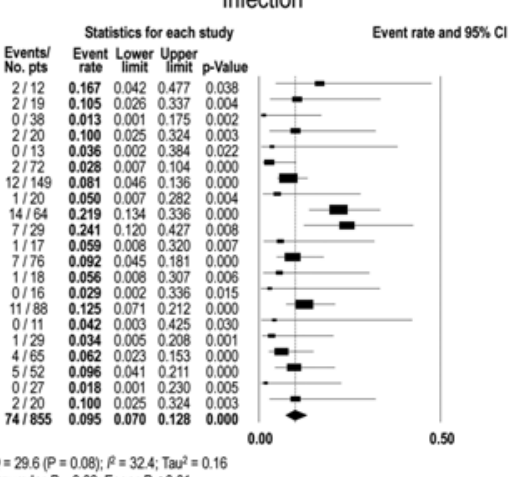

Heterogeneity Cochran $Q=29.6(P=0.08) ; \beta=324 ;$ Tau $2=0.16$

\section{C}

Study name

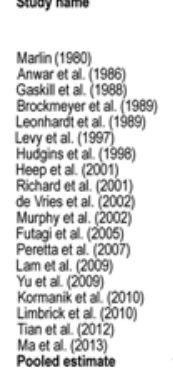

Arrest of hydrocephalus

Statistics for each study
Event Lomer Uppert
rate

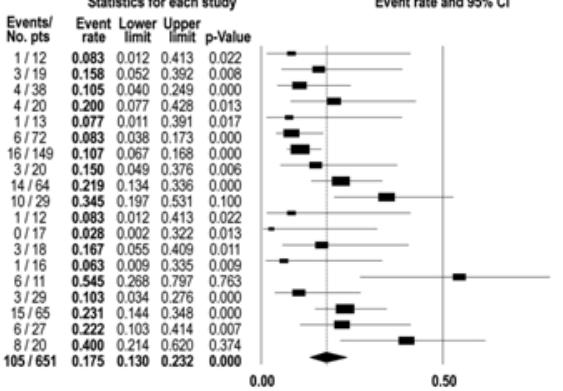

Heterogeneity Coctran $Q=38.7(P<0.01) ; \beta=53.5 ; \quad \mathrm{Tau}^{2}=0.28$

\section{D}

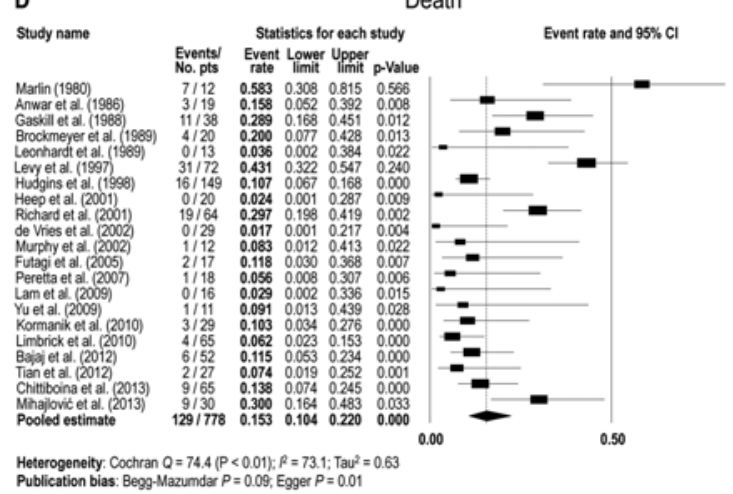

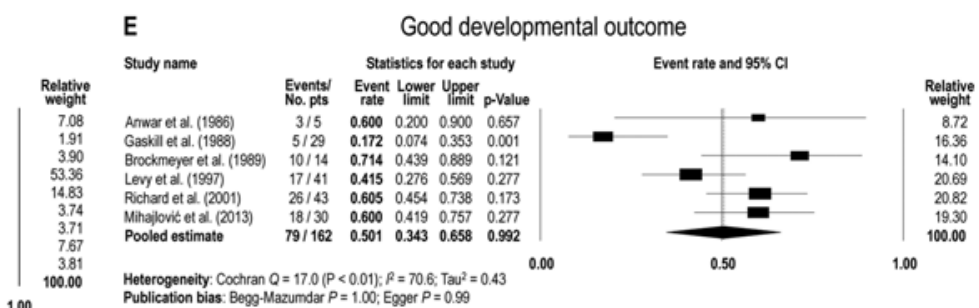

$\int_{1.00} 1000$

$\mathrm{F}$

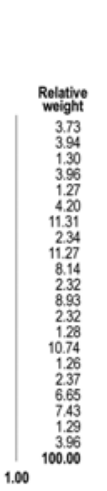

Study name

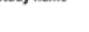

Marlin (1980)
Anwar et al. (1986)

Brockmeyer ef al. (1989)

Leorhar et al (1997)

Hudgins. et al. (1998)

Heepet al. $(2001)$
Richard et al. $(2001)$

Broumere ef al. 20008

Peretta ef al. (2007)

Kormet al. (2009)

Kormanik et al (2010)

Tiantict al. (2012)

$\begin{array}{lllllll}71 / 653 & 0.108 & 0.074 & 0.155 & 0.000\end{array}$

Heterogeneity: Cochran $Q=24.8(P=0.03) ; P=47.5 ; \operatorname{Tau}^{2}=0.24$

Revision
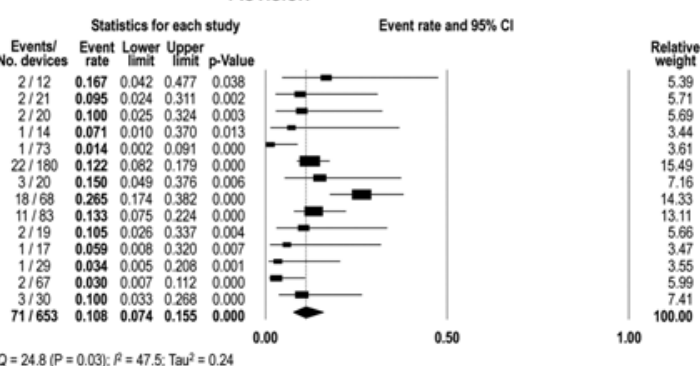

Publication bias: Begg-Mazumdar $P=0.19$, Egger $P=0.02$

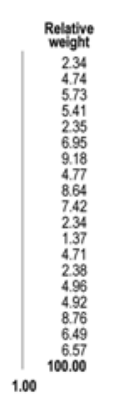

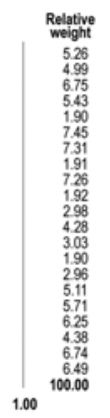

FIG. 3. Forest plots of meta-analyses of outcomes and complications of VAD for treatment of PHVD in preterm infants. Obstruction (A); infection (B); arrest of hydrocephalus (C); death (D); good neurodevelopmental outcome (E); and revision (F).

outcome, and $47.3 \%$ (95\% CI 29.7-65.7) for surgical revision (Fig. 4).

\section{Discussion}

Our study aimed to provide a synthesis of the available evidence concerning the use of VSGSs, VADs, and EVDs as temporizing devices for PHVD/PHH in preterm infants. We conducted a comprehensive search of the world literature and determined pooled summary estimates for several outcomes of interest. The greatest limitation of our study, as with most meta-analyses, is heterogeneity, for which there are many causes. The baseline populations in the primary studies probably differed in many ways, 


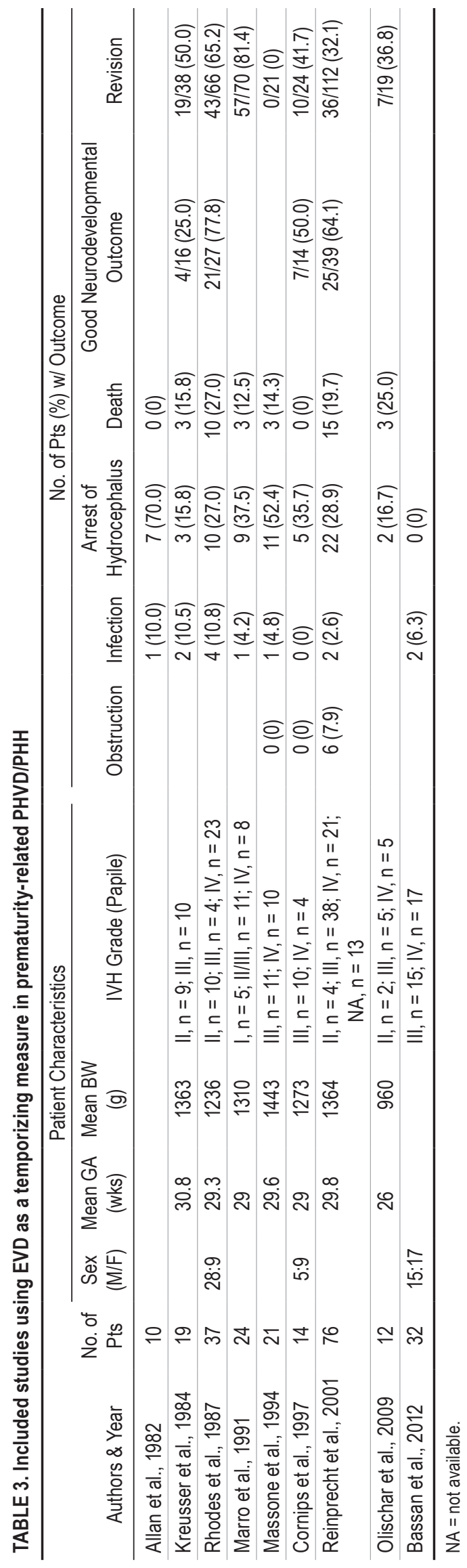

including factors such as birth weight, gestational age at birth, and severity of IVH. Definitions of outcomes were not standardized among studies and so probably differed as well. Length of follow-up and statistical methods also varied among studies. Moreover, it is well recognized that there exist wide variations in practice patterns among different institutions ${ }^{56}$ (including differing thresholds for surgical intervention and ancillary methods of medical management). Such variation almost certainly existed among the wide geographic and temporal range of our primary studies.

Such clinical heterogeneity, although almost certainly present in our primary studies, is very difficult to identify from published data. Statistical heterogeneity, however, is more objectively defined and easier to identify. We did find, for example, that statistical heterogeneity was generally low for the outcomes of infection, obstruction, arrest of hydrocephalus, and revision. That is, the outcomes reported were relatively consistent among studies. By contrast, there was substantial statistical heterogeneity among reported mortality rates and neurodevelopmental outcomes. This precluded us from being able to make meaningful comparisons between groups with respect to these latter outcomes.

This is perhaps not surprising. Certainly, IVH and $\mathrm{PHVD} / \mathrm{PHH}$ are known to present with a very wide spectrum of clinical severity, so outcomes can be expected to vary between cohorts. ${ }^{49,52}$ These outcomes, in particular, are influenced to a great extent by a number of factors, e.g., gestational age, birth weight, grade of IVH, and the presence of other complications of prematurity. In addition, neurodevelopmental outcome is hard to quantify, and definitions of good neurodevelopmental outcome varied widely among included articles. For example, some studies relied on motor outcome, whereas others evaluated intellect, and still others used language. Because of all of these limitations, the present study represents only a current snapshot of the existing literature and cannot replace high-quality comparative studies, of which very few currently exist.

The 2 most common methods used to temporarily treat PHVD are VSGS and VAD, and there has appropriately been much interest in this comparison. One practical advantage that VSGSs offer over VADs is the ability to divert CSF to an anatomical compartment where it is directly reabsorbed into the body, thus circumventing the need for external CSF removal (i.e., serial tapping). In theory, this reduces the risk of infection. On the other hand, the maintenance of a closed system prevents the removal and allows the buildup of blood products and debris that may block the system, possibly increasing risk of mechanical failure. We found a slightly lower rate of infection $(9.2 \%$ vs $9.5 \%$ ) and higher rate of obstruction $(9.6 \%$ vs $7.3 \%)$ with VSGSs compared with VADs. However, the $95 \%$ CIs overlapped, suggesting no statistically significant difference.

In 2009, Wellons and colleagues ${ }^{66}$ published the results of a multicenter retrospective series examining conversion from temporary to permanent CSF diversion in infants with PHVD/PHH. This group observed a statistically significant difference in permanent shunt rate for premature infants temporized with VAD (61 of 88 patients [69\%]) versus 
A

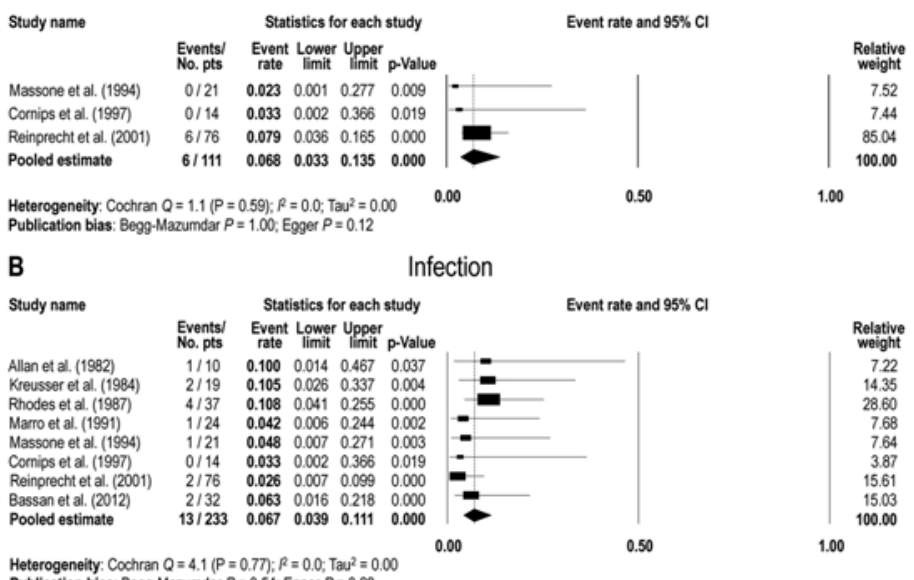

Publication bins: Bogan $Q=4.1(P=0.7), P=0.0, \operatorname{Tau}^{2}=0.00$

C

Study name
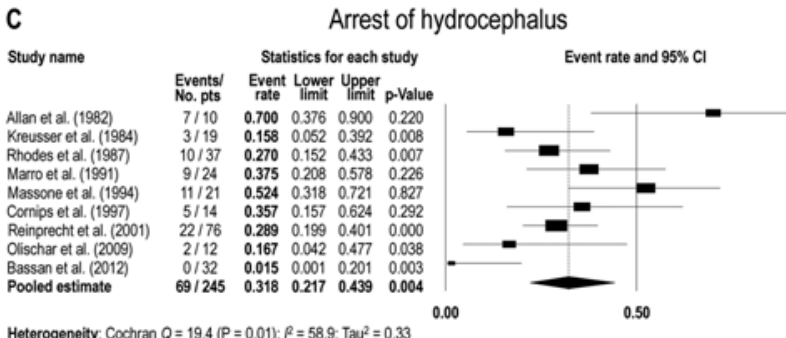

Arrest of hydrocephalus

Heterogeneity: Cochran $Q=19.4(P=0.01) ; R=58.9 ; \operatorname{Tau}^{2}=0.33$ Pubserat

D

Study name

Allan et al. (1982)

Kreusser et al. (1984)

Rhodes et al. (1987)
Marro et al. (1991)

Massone et al. (1994)

Comips et al. (1997)

Reinprecht et al. (2001)
Olischar et al. (2009)

Pooled estimate

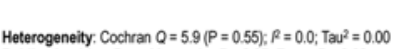

Death

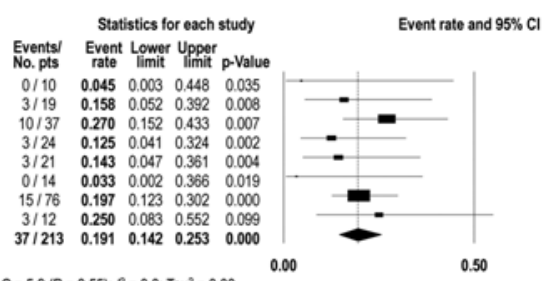

0.50

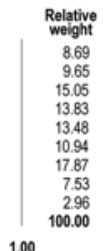

1.00

ive

7.52

85.04

.

E

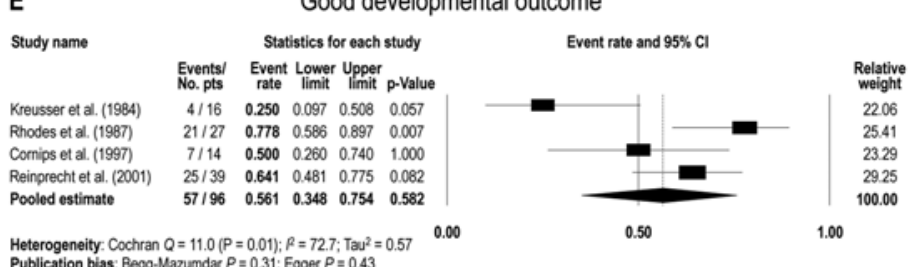

Heterogeneity. Cochran $Q=11.0(P=0.01) ; R=72.7 ;$ Tau $^{2}=0.57$
Publication bias: Begg-Mazumdar $P=0.31 ;$ Egger $P=0.43$

F

Study name

Revision

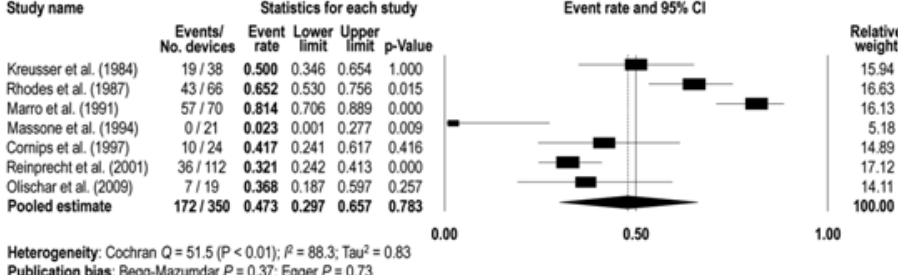

FIG. 4. Forest plots of meta-analyses of outcomes and complications of EVD for treatment of PHVD in preterm infants. Obstruction (A); infection (B); arrest of hydrocephalus (C); death (D); good neurodevelopmental outcome (E); and revision (F).

VSGS (31 of 36 patients [86\%]). A theoretical advantage often described for VSGS is the so-called back-pressure provided by the subgaleal space; this is believed to provide a driving force to kick-start the CSF absorptive pathways.
However, blood and debris are hypothesized to activate an inflammatory process mediated by various cytokines, such as tumor necrosis factor (TNF)- $\alpha$ and transforming growth factor (TGF)- $\beta$; these stimulate the deposition of 
extracellular matrix proteins, which ultimately obstruct CSF pathways. ${ }^{35,58,59,68}$

The elimination of such cytokines by serial tapping may contribute to a lower shunt rate with use of VADs. On the other hand, CSF is thought to contain neurotrophic factors and molecules involved in nervous system signaling. ${ }^{43,65}$ Hence, CSF removal may have important implications for CNS development and function. In our study, we found VADs resulted in only a very slightly higher incidence of arrest of hydrocephalus that was not statistically significant (17.5\% vs $13.9 \%)$. Neurodevelopmental outcomes were comparable for VADs and VSGSs after accounting for heterogeneity.

An important alternative to VADs and VSGSs are EVDs, which are used in many different settings to temporarily treat hydrocephalus, perhaps the most notable being subarachnoid hemorrhage. ${ }^{21}$ As with VSGSs, EVDs allow continuous drainage of $\mathrm{CSF}$, without requiring repeated taps. However, like VADs, these devices also allow blood, debris, and inflammatory cytokines to be removed from the ventricular space to the external environment. We observed slightly lower rates of obstruction (6.8\%) and infection $(6.7 \%)$ for patients treated with EVDs compared with VADs and VSGSs, but again, these were not statistically significant. Although the external hardware of an EVD theoretically provides a route of entry into the CNS for microbes, the rates of infection and obstruction may have been lower because EVDs are often routinely replaced as a precautionary measure.

Indeed, as expected, the revision rate of EVDs (47.3\%) was significantly greater than that of VADs $(10.8 \%)$ or VSGSs (12.2\%). However, it was not possible to discern from the information presented in individual articles what proportion of these revisions was elective versus secondary to failure. Furthermore, the rates of infection and obstruction reported in our study are consistent with those reported for EVDs in various other contexts. ${ }^{18,29,47,61}$ Interestingly, the rate of arrest of PHVD was substantially higher for treatment with EVD (31.8\%) versus VAD (17.5\%) or VSGS (13.9\%). For the comparison between EVD and VSGS, this difference reached statistical significance, as indicated by the nonoverlapping CIs.

One hypothesis for this unexpected finding is that all EVDs require eventual removal, forcing a decision to either convert to a permanent shunt, or to stop CSF diversion altogether. The latter may result in a more thorough trial of the natural primary and secondary CSF pathways and a final opportunity to avoid permanent shunting in the infant. Given the numerous confounding factors and heterogeneity that we could not control for, it was not possible to fully attribute this difference to the use of EVDs alone. However, it is worthy of further investigation.

Importantly, our study does not, and cannot, replace the need for well-designed prospective comparative studies addressing these questions. Key components of a robust study on this topic would include randomization; stratification of patients by relevant prognostic factors, e.g., gestational age, grade of IVH, and presence/absence of other complications of prematurity; and multi-institutional design to generate sufficient power. Given the results presented here, we recommend direct comparison of EVD in addition to VSGS and VAD for treatment of PHVD in preterm infants.

\section{Conclusions}

Our study provides a useful summary of the current literature on outcomes related to the use of VSGSs, VADs, and EVDs in the treatment of prematurity-related PVHD/ PHH. The results of prospective comparative studies in this area will provide further, much-needed insights.

\section{References}

1. Adams-Chapman I, Hansen NI, Stoll BJ, Higgins R: Neurodevelopmental outcome of extremely low birth weight infants with posthemorrhagic hydrocephalus requiring shunt insertion. Pediatrics 121:e1167-e1177, 2008

2. Alan N, Manjila S, Minich N, Bass N, Cohen AR, Walsh M, et al: Reduced ventricular shunt rate in very preterm infants with severe intraventricular hemorrhage: an institutional experience. J Neurosurg Pediatr 10:357-364, 2012

3. Allan WC, Holt PJ, Sawyer LR, Tito AM, Meade SK: Ventricular dilation after neonatal periventricular-intraventricular hemorrhage. Natural history and therapeutic implications. Am J Dis Child 136:589-593, 1982

4. Ananth CV, Vintzileos AM: Epidemiology of preterm birth and its clinical subtypes. J Matern Fetal Neonatal Med 19:773-782, 2006

5. Anwar M, Doyle AJ, Kadam S, Hiatt IM, Hegyi T: Management of posthemorrhagic hydrocephalus in the preterm infant. J Pediatr Surg 21:334-337, 1986

6. Bajaj M, Lulic-Botica M, Natarajan G: Evaluation of cerebrospinal fluid parameters in preterm infants with intraventricular reservoirs. J Perinatol 32:786-790, 2012

7. Bassan H, Eshel R, Golan I, Kohelet D, Ben Sira L, Mandel $\mathrm{D}$, et al: Timing of external ventricular drainage and neurodevelopmental outcome in preterm infants with posthemorrhagic hydrocephalus. Eur J Paediatr Neurol 16:662-670, 2012

8. Begg CB, Mazumdar M: Operating characteristics of a rank correlation test for publication bias. Biometrics 50:10881101,1994

9. Blencowe H, Cousens S, Oestergaard MZ, Chou D, Moller AB, Narwal R, et al: National, regional, and worldwide estimates of preterm birth rates in the year 2010 with time trends since 1990 for selected countries: a systematic analysis and implications. Lancet 379:2162-2172, 2012

10. Brockmeyer DL, Wright LC, Walker ML, Ward RM: Management of posthemorrhagic hydrocephalus in the low-birthweight preterm neonate. Pediatr Neurosci 15:302-308, 1989

11. Brouwer AJ, Brouwer MJ, Groenendaal F, Benders MJ, Whitelaw A, de Vries LS: European perspective on the diagnosis and treatment of posthaemorrhagic ventricular dilatation. Arch Dis Child Fetal Neonatal Ed 97:F50-F55, 2012

12. Brouwer A, Groenendaal F, van Haastert IL, Rademaker K, Hanlo P, de Vries L: Neurodevelopmental outcome of preterm infants with severe intraventricular hemorrhage and therapy for post-hemorrhagic ventricular dilatation. J Pediatr 152:648-654, 2008

13. Chittiboina P, Pasieka H, Sonig A, Bollam P, Notarianni C, Willis BK, et al: Posthemorrhagic hydrocephalus and shunts: what are the predictors of multiple revision surgeries? J Neurosurg Pediatr 11:37-42, 2013

14. Cornips E, Van Calenbergh F, Plets C, Devlieger H, Casaer P: Use of external drainage for posthemorrhagic hydrocephalus in very low birth weight premature infants. Childs Nerv Syst 13:369-374, 1997

15. de Vries LS, Liem KD, van Dijk K, Smit BJ, Sie L, Rademak- 
er KJ, et al: Early versus late treatment of posthaemorrhagic ventricular dilatation: results of a retrospective study from five neonatal intensive care units in The Netherlands. Acta Paediatr 91:212-217, 2002

16. Egger M, Davey Smith G, Schneider M, Minder C: Bias in meta-analysis detected by a simple, graphical test. BMJ 315:629-634, 1997

17. Eichenwald EC, Stark AR: Management and outcomes of very low birth weight. N Engl J Med 358:1700-1711, 2008

18. Flint AC, Rao VA, Renda NC, Faigeles BS, Lasman TE, Sheridan W: A simple protocol to prevent external ventricular drain infections. Neurosurgery 72:993-999, 2013

19. Futagi Y, Suzuki Y, Toribe Y, Nakano H, Morimoto K: Neurodevelopmental outcome in children with posthemorrhagic hydrocephalus. Pediatr Neurol 33:26-32, 2005

20. Gaskill SJ, Marlin AE, Rivera S: The subcutaneous ventricular reservoir: an effective treatment for posthemorrhagic hydrocephalus. Childs Nerv Syst 4:291-295, 1988

21. Gigante P, Hwang BY, Appelboom G, Kellner CP, Kellner MA, Connolly ES: External ventricular drainage following aneurysmal subarachnoid haemorrhage. Br J Neurosurg 24:625-632, 2010

22. Heep A, Engelskirchen R, Holschneider A, Groneck P: Primary intervention for posthemorrhagic hydrocephalus in very low birthweight infants by ventriculostomy. Childs Nerv Syst 17:47-51, 2001

23. Heuchan AM, Evans N, Henderson Smart DJ, Simpson JM: Perinatal risk factors for major intraventricular haemorrhage in the Australian and New Zealand Neonatal Network, 1995-97. Arch Dis Child Fetal Neonatal Ed 86:F86-F90, 2002

24. Higgins JP, Thompson SG, Deeks JJ, Altman DG: Measuring inconsistency in meta-analyses. BMJ 327:557-560, 2003

25. Hudgins RJ, Boydston WR, Gilreath CL: Treatment of posthemorrhagic hydrocephalus in the preterm infant with a ventricular access device. Pediatr Neurosurg 29:309-313, 1998

26. Karas CS, Baig MN, Elton SW: Ventriculosubgaleal shunts at Columbus Children's Hospital: Neurosurgical implant placement in the neonatal intensive care unit. J Neurosurg 107:220-223, 2007

27. Klebermass-Schrehof K, Czaba C, Olischar M, Fuiko R, Waldhoer T, Rona Z, et al: Impact of low-grade intraventricular hemorrhage on long-term neurodevelopmental outcome in preterm infants. Childs Nerv Syst 28:2085-2092, 2012

28. Köksal V, Oktem S: Ventriculosubgaleal shunt procedure and its long-term outcomes in premature infants with posthemorrhagic hydrocephalus. Childs Nerv Syst 26:15051515,2010

29. Korinek AM, Reina M, Boch AL, Rivera AO, De Bels D, Puybasset L: Prevention of external ventricular drain-related ventriculitis. Acta Neurochir (Wien) 147:39-46, 2005

30. Kormanik K, Praca J, Garton HJ, Sarkar S: Repeated tapping of ventricular reservoir in preterm infants with post-hemorrhagic ventricular dilatation does not increase the risk of reservoir infection. J Perinatol 30:218-221, 2010

31. Kreusser KL, Tarby TJ, Taylor D, Kovnar E, Hill A, Conry JA, et al: Rapidly progressive posthemorrhagic hydrocephalus. Treatment with external ventricular drainage. Am J Dis Child 138:633-637, 1984

32. Lam HP, Heilman CB: Ventricular access device versus ventriculosubgaleal shunt in post hemorrhagic hydrocephalus associated with prematurity. J Matern Fetal Neonatal Med 22:1097-1101, 2009

33. Lemons JA, Bauer CR, Oh W, Korones SB, Papile LA, Stoll BJ, et al: Very low birth weight outcomes of the National Institute of Child health and human development neonatal research network, January 1995 through December 1996. Pediatrics 107:E1, 2001
34. Leonhardt A, Steiner HH, Linderkamp O: Management of posthaemorrhagic hydrocephalus with a subcutaneous ventricular catheter reservoir in premature infants. Arch Dis Child 64:24-28, 1989

35. Leviton A, Gilles F: Ventriculomegaly, delayed myelination, white matter hypoplasia, and "periventricular" leukomalacia: how are they related? Pediatr Neurol 15:127-136, 1996

36. Levy ML, Masri LS, McComb JG: Outcome for preterm infants with germinal matrix hemorrhage and progressive hydrocephalus. Neurosurgery 41:1111-1118, 1997

37. Limbrick DD, Jr., Mathur A, Johnston JM, Munro R, Sagar J, Inder T, et al: Neurosurgical treatment of progressive posthemorrhagic ventricular dilation in preterm infants: a 10-year single-institution study. J Neurosurg Pediatr 6:224-230, 2010

38. Ma XN, Kong XY, Han TY, Chen Y, Huang JJ, Feng ZC: [Therapeutic effect of Ommaya reservoir implantation on hydrocephalus in premature infants following intraventricular hemorrhage and factors associted with the therapeutic effect.] Zhongguo Dang Dai Er Ke Za Zhi 15:327-331, 2013 (Chinese)

39. Marlin AE: Protection of the cortical mantle in premature infants with posthemorrhagic hydrocephalus. Neurosurgery 7:464-468, 1980

40. Marro PJ, Dransfield DA, Mott SH, Allan WC: Posthemorrhagic hydrocephalus. Use of an intravenous-type catheter for cerebrospinal fluid drainage. Am J Dis Child 145:1141-1146, 1991

41. Massone ML, Cama A, Leone D, Pellas E, Vallarino R, Carini S, et al: [Results of early external ventricular diversion in posthemorrhagic ventricular dilatation in the newborn.] Minerva Anestesiol 60:663-668, 1994 (Ital)

42. Mihajlovic M, Bogosavljevic V, Nikolic I, Mrdak M, Repac N, Scepanovic V, et al: Surgical treatment problems of hydrocephalus caused by spontaneus intraventricular hemorrhage in prematurely born children. Turk Neurosurg 23:593-599, 2013

43. Miyan JA, Zendah M, Mashayekhi F, Owen-Lynch PJ: Cerebrospinal fluid supports viability and proliferation of cortical cells in vitro, mirroring in vivo development. Cerebrospinal Fluid Res 3:2, 2006

44. Moher D, Liberati A, Tetzlaff J, Altman DG: Preferred reporting items for systematic reviews and meta-analyses: the PRISMA statement. J Clin Epidemiol 62:1006-1012, 2009

45. Murphy BP, Inder TE, Rooks V, Taylor GA, Anderson NJ, Mogridge N, et al: Posthaemorrhagic ventricular dilatation in the premature infant: natural history and predictors of outcome. Arch Dis Child Fetal Neonatal Ed 87:F37-F41, 2002

46. Nagy A, Bognar L, Pataki I, Barta Z, Novak L: Ventriculosubgaleal shunt in the treatment of posthemorrhagic and postinfectious hydrocephalus of premature infants. Childs Nerv Syst 29:413-418, 2013

47. Ngo QN, Ranger A, Singh RN, Kornecki A, Seabrook JA, Fraser DD: External ventricular drains in pediatric patients. Pediatr Crit Care Med 10:346-351, 2009

48. Olischar M, Klebermass K, Hengl B, Hunt RW, Waldhoer T, Pollak A, et al: Cerebrospinal fluid drainage in posthaemorrhagic ventricular dilatation leads to improvement in amplitude-integrated electroencephalographic activity. Acta Paediatr 98:1002-1009, 2009

49. Payne AH, Hintz SR, Hibbs AM, Walsh MC, Vohr BR, Bann $\mathrm{CM}$, et al: Neurodevelopmental outcomes of extremely lowgestational-age neonates with low-grade periventricular-intraventricular hemorrhage. JAMA Pediatr 167:451-459, 2013

50. Peretta P, Ragazzi P, Carlino CF, Gaglini P, Cinalli G: The role of Ommaya reservoir and endoscopic third ventriculostomy in the management of post-hemorrhagic hydrocephalus of prematurity. Childs Nerv Syst 23:765-771, 2007 
51. Rahman S, Teo C, Morris W, Lao D, Boop FA: Ventriculosubgaleal shunt: a treatment option for progressive posthemorrhagic hydrocephalus. Childs Nerv Syst 11:650-654, 1995

52. Resch B, Gedermann A, Maurer U, Ritschl E, Müller W: Neurodevelopmental outcome of hydrocephalus following intra-/periventricular hemorrhage in preterm infants: shortand long-term results. Childs Nerv Syst 12:27-33, 1996

53. Reinprecht A, Dietrich W, Berger A, Bavinzski G, Weninger $\mathrm{M}$, Czech T: Posthemorrhagic hydrocephalus in preterm infants: long-term follow-up and shunt-related complications. Childs Nerv Syst 17:663-669, 2001

54. Rhodes TT, Edwards WH, Saunders RL, Harbaugh RE, Little CL, Morgan LJ, et al: External ventricular drainage for initial treatment of neonatal posthemorrhagic hydrocephalus: surgical and neurodevelopmental outcome. Pediatr Neurosci 13:255-262, 1987

55. Richard E, Cinalli G, Assis D, Pierre-Kahn A, Lacaze-Masmonteil T: Treatment of post-haemorrhage ventricular dilatation with an Ommaya's reservoir: management and outcome of 64 preterm infants. Childs Nerv Syst 17:334-340, 2001

56. Riva-Cambrin J, Shannon CN, Holubkov R, Whitehead WE, Kulkarni AV, Drake J, et al: Center effect and other factors influencing temporization and shunting of cerebrospinal fluid in preterm infants with intraventricular hemorrhage. J Neurosurg Pediatr 9:473-481, 2012

57. Roze E, Van Braeckel KN, van der Veere CN, Maathuis CG, Martijn A, Bos AF: Functional outcome at school age of preterm infants with periventricular hemorrhagic infarction. Pediatrics 123:1493-1500, 2009

58. Sävman K, Blennow M, Hagberg H, Tarkowski E, Thoresen $\mathrm{M}$, Whitelaw A: Cytokine response in cerebrospinal fluid from preterm infants with posthaemorrhagic ventricular dilatation. Acta Paediatr 91:1357-1363, 2002

59. Shooman D, Portess H, Sparrow O: A review of the current treatment methods for posthaemorrhagic hydrocephalus of infants. Cerebrospinal Fluid Res 6:1, 2009

60. Sklar F, Adegbite A, Shapiro K, Miller K: Ventriculosubgaleal shunts: management of posthemorrhagic hydrocephalus in premature infants. Pediatr Neurosurg 18:263-265, 1992

61. Stangl AP, Meyer B, Zentner J, Schramm J: Continuous external CSF drainage-a perpetual problem in neurosurgery. Surg Neurol 50:77-82, 1998

62. Stoelhorst GM, Rijken M, Martens SE, Brand R, den Ouden $\mathrm{AL}$, Wit JM, et al: Changes in neonatology: comparison of two cohorts of very preterm infants (gestational age $<32$ weeks): the Project On Preterm and Small for Gestational Age Infants 1983 and the Leiden Follow-Up Project on Prematurity 1996-1997. Pediatrics 115:396-405, 2005

63. Stroup DF, Berlin JA, Morton SC, Olkin I, Williamson GD, Rennie D, et al: Meta-analysis of observational studies in epidemiology: a proposal for reporting. Meta-analysis Of
Observational Studies in Epidemiology (MOOSE) group. JAMA 283:2008-2012, 2000

64. Tian AG, Hintz SR, Cohen RS, Edwards MS: Ventricular access devices are safe and effective in the treatment of posthemorrhagic ventricular dilatation prior to shunt placement. Pediatr Neurosurg 48:13-20, 2012

65. Veening JG, Barendregt HP: The regulation of brain states by neuroactive substances distributed via the cerebrospinal fluid; a review. Cerebrospinal Fluid Res 7:1, 2010

66. Wellons JC, Shannon CN, Kulkarni AV, Simon TD, RivaCambrin J, Whitehead WE, et al: A multicenter retrospective comparison of conversion from temporary to permanent cerebrospinal fluid diversion in very low birth weight infants with posthemorrhagic hydrocephalus. J Neurosurg Pediatr 4:50-55, 2009

67. Wells GA, Shea B, O'Connell D, Peterson J, Welch V, Losos $\mathrm{M}$, et al: The Newcastle-Ottawa Scale (NOS) for assessing the quality of nonrandomized studies in meta-analyses. Ottawa Hospital Research Institute. (http://www.ohri.ca/ programs/clinical_epidemiology/oxford.asp) [Accessed June $4,2015]$

68. Whitelaw A, Christie S, Pople I: Transforming growth factor-beta1: a possible signal molecule for posthemorrhagic hydrocephalus? Pediatr Res 46:576-580, 1999

69. Yu B, Li S, Lin Z, Zhang N: Treatment of posthemorrhagic hydrocephalus in premature infants with subcutaneous reservoir drainage. Pediatr Neurosurg 45:119-125, 2009

\section{Disclosure}

The authors report no conflict of interest concerning the materials or methods used in this study or the findings specified in this paper.

\section{Author Contributions}

Conception and design: Kulkarni, Badhiwala, CJ Hong. Acquisition of data: Kulkarni, Badhiwala, CJ Hong, BY Hong, RivaCambrin. Analysis and interpretation of data: all authors. Drafting the article: Badhiwala, CJ Hong, Nassiri. Critically revising the article: all authors. Reviewed submitted version of manuscript: all authors. Approved the final version of the manuscript on behalf of all authors: Kulkarni. Statistical analysis: Badhiwala, Nassiri. Administrative/technical/material support: Kulkarni, Riva-Cambrin. Study supervision: Kulkarni, Riva-Cambrin.

\section{Correspondence}

Abhaya V. Kulkarni, Division of Neurosurgery, The Hospital for Sick Children, 555 University Ave., Rm. 1503, Toronto, ON M5G 1X8, Canada. email: abhaya.kulkarni@sickkids.ca. 